\title{
Original Research \\ Effects of maternal hypertension on the neonatal haemogram in southern Nigeria: A case-control study
}

\author{
Helen C. Okoye ${ }^{1}$, Lisa I. Eweputanna², Kaladada I. Korubo ${ }^{3}$, Oseikhuemen A. Ejele \\ 1. Department of Haematology and Immunology, University of Nigeria, Enugu Campus, Enugu, Nigeria \\ 2. Department of Radiology, University of Port Harcourt Teaching Hospital, Port Harcourt, Nigeria \\ 3. Department of Haematology and Blood Transfusion, University of Port Harcourt Teaching Hospital, Port Harcourt, Nigeria
}

Correspondence: Dr Helen C. Okoye (helenc.okoye@unn.edu.ng)

\begin{abstract}
Background
Abstract

Hypertension in pregnancy is a leading cause of maternal and neonatal morbidity and mortality. This study aimed to compare the hematological parameters in neonates of hypertensive mothers with those of normotensive mothers, and also to compare the incidence of polycythaemia, neutropenia and thrombocytopenia in both groups.

Methods

This was a hospital-based case control study. Three milliliters of cord blood from neonates of women with hypertension in pregnancy and those of normotensive pregnant women were sampled for haemogram parameters using a 3-part autoanalyser. Haematocrit and white blood cell differentials were done manually. Data were analysed using SPSS version 16.

Results

A total of 200 neonates were recruited, comprising 100 neonates of mothers with hypertensive disorders of pregnancy and 100 neonates of normotensive mothers. The mean haematocrit was significantly higher in neonates of hypertensive mothers than those of normotensive mothers. The neutrophil and platelet counts of neonates of hypertensive mothers were significantly lower than those of normotensive mothers. The incidences of polycythaemia, neutropenia, and thrombocytopenia were found to be $8 \%, 15 \%$, and $38 \%$ among neonates of hypertensive mothers and $0 \%, 2 \%$, and $8 \%$ among neonates of normotensive mothers, respectively. These incidences were significantly different between the groups.

Conclusions

There was a positive association between hypertension in pregnancy and neonatal polycythaemia, neutropenia, and thrombocytopenia. Haematological parameters of neonates of mothers with hypertension in pregnancy should be properly evaluated and monitored to reduce the chances of developing
\end{abstract} complications associated with these abnormalities.

\section{Introduction}

The World Health Organization (WHO) estimates that about 4.3 million stillbirths and 3.4 million deaths occur during the first week of life annually, with $98 \%$ of these deaths occurring in developing countries. ${ }^{1}$ Deaths occurring in the first days and weeks of life most often result from events in utero and during birth, rather than as consequences of the external environment into which the baby is born, and thus are closely associated with the mother's health and healthcare.

Hypertension in pregnancy (HIP) constitutes a major health burden in the obstetric population, as it is one of the leading causes of maternal and perinatal morbidity and mortality. ${ }^{2}$ HIP can be defined as diastolic blood pressure of at least 90 $\mathrm{mmHg}$, a systolic blood pressure of at least $140 \mathrm{mmHg}$, a rise in diastolic blood pressure by at least $15 \mathrm{mmHg}$, or a rise by $30 \mathrm{mmHg}$ in systolic blood pressure in a pregnant woman on at least two different occasions at least 6 hours apart. ${ }^{3,4} \mathrm{HIP}$ disorders complicate about $12 \%$ to $22 \%$ of pregnancies. $^{2}$ In the United States, pregnancy-related deaths have been found to be 2 to 3 times more common in blacks than in white women with HIP, accounting for $16 \%$ of the deaths. ${ }^{5}$ The American College of Obstetricians and Gynecologists, and the United Nations Organization recognise four categories of HIP. These include chronic hypertension, gestational hypertension, preeclampsia/eclampsia, and superimposed preeclampsia/eclampsia (a condition defined as chronic hypertension complicated by preeclampsia/ eclampsia). ${ }^{1,2,6}$ Haemolysis, elevated liver enzymes and low platelets (HELLP) syndrome is considered a complication of severe preeclampsia. Preeclampsia can be mild or severe.

http://dx.doi.org/10.4314/mmj.v28i4.5
Hypertension is said to be mild when the blood pressures are less than $160 / 110 \mathrm{mmHg}$, whereas it is severe when blood pressures are above the $160 / 110 \mathrm{mmHg}$ threshold. ${ }^{4}$

Hypertension gives rise to a range of maternal and foetal complications. The maternal complications are a result of the high blood pressure itself, and the effects of the hypertension on different organs. These complications include thrombocytopenia, disseminated intravascular coagulation (DIC), placental abruption, oliguria, renal failure, pulmonary oedema, permanent visual disturbances, intracranial haemorrhage and stroke, hepatic failure, and cardiovascular collapse. The foetal and neonatal complications basically arise from hypoxia and acute or chronic uteroplacental insufficiency. ${ }^{7,8,9,10}$ These complications include a range of haematological derangements, such as polycythaemia, ${ }^{7,8}$ which is 12.6 times more prevalent among children born to mothers with HIP than in the general population; ${ }^{8}$ neutropenia, which is also observed to be prolonged in this group of neonates with attendant higher risk of nosocomial infections; ${ }^{9}$ thrombocytopenia, occurring in as many as $22 \%$ of these infants; ${ }^{10}$ and some coagulation disorders. ${ }^{11}$ Other foetal and neonatal complications are intrauterine growth restriction, prematurity, and bronchopulmonary dysplasia.

There is a dearth of published data on haematological findings in neonates (infants within the first 28 days of life) in Nigeria, despite the high prevalence of maternal hypertension and perinatal mortality in our population, ${ }^{5}$ as well as the observed racial variations in blood counts, ${ }^{12,13}$ wherein black individuals are known to have lower neutrophil and platelet counts. The purpose of this study was to determine the haematological values among neonates of hypertensive mothers, with particular reference to their haemogram.

MMJ VOL 28 (4): December 2016 


\section{Methods}

\section{Study site and design}

This was a hospital-based case control study, conducted at the University of Port Harcourt Teaching Hospital (UPTH), Rivers State, Nigeria, from July 2013 to December 2013.

\section{Study population, sample size, and recruitment}

A total of 200 study participants, who were recruited from the labour wards or theatre were placed in two groups: the case group, which was comprised of 100 neonates delivered to pregnant women with hypertension in pregnancy (HIP); and the control group, made up of 100 neonates delivered to normotensive pregnant women, matched for gestational age and parity with the case group. They were recruited using a systematic random sampling method through the labour wards and theatres. The obstetrics unit of the hospital delivers about two new hypertensive mothers daily, giving a total of 10 cases in a week.

The study was designed to be carried out over a period of 6 months, during which about 240 mothers with hypertension were expected to deliver.

Therefore, using the formulae $\mathrm{N} / \mathrm{n}=\mathrm{k}$

Where: $\mathrm{N}=$ total number of cases seen; $\mathrm{n}=$ sample size for cases; $\mathrm{k}=$ interval

$\mathrm{k}=240 / 100=2.4 \approx 2$

Following this calculation, the number 1 was randomly chosen (between 1 and 2) as a daily starting point. Starting with the first patient seen each day, every other patient seen that satisfied the inclusion criteria was recruited. Mothers who met the selection criteria for the control group were selected the same way. Demographic data, obstetric history, data on hypertensive disorders of pregnancy, and birth outcomes were documented from the case notes, as well as using a structured questionnaire. Those who required emergency caesarean sections were followed to the theatre for further data and sample collection. The newborns of all cases and controls were sampled for haematological analysis. Neonates born from mothers who were diagnosed and managed for HIP, as well as full-term apparently healthy neonates born to normotensive mothers, without maternal complications, matched for gestational age with the test group, served as the case and control groups, respectively.

\section{Inclusion and exclusion criteria}

Subjects were excluded at the point of recruitment when they checked into the labour wards or theatre if they had any of the following features: multiple pregnancies, diabetes mellitus, renal or heart diseases, or a history of chronic pulmonary disease or smoking. Others were excluded during or after labour if they had twin-twin transfusion syndrome, delayed cord clamping, delayed labour below the level of mother's introitus, cord milking, babies born to mothers whose pregnancies were complicated by any other risk factors for increase in maternal or foetal morbidity and mortality, such as Rh incompatibility, and babies born with congenital malformations and birth asphyxia.

\section{Postpartum data collection}

Details of labour, mode of delivery, and presence of complications were obtained for each neonate, as well as the sex, date and time of birth, and Apgar score.

\section{Diagnostic considerations}

Mothers were diagnosed with HIP based on the following:

- Chronic hypertension: blood pressrure (BP) $\geq$

$140 / 90 \mathrm{mmHg}$, diagnosed before 20 weeks gestational age (GA)

- Preeclampsia/eclampsia: BP $\geq 140 / 90 \mathrm{mmHg}$ after 20 weeks GA, with proteinuria of $\geq 300 \mathrm{mg} / 24$ hours, or $\geq 1+$ on dipstick \pm seizures

- Chronic hypertension with superimposed preeclampsia: $\mathrm{BP} \geq 140 / 90 \mathrm{mmHg}$ before 20 weeks GA but with new onset proteinuria $(\geq 300 \mathrm{mg} / 24$ hours or $\geq 1+$ dipstick) occurring after 20 weeks GA

- Gestational hypertension: BP $\geq 140 / 90 \mathrm{mmHg}$ for the first time after 20 weeks GA during pregnancy and without proteinuria

- Cases were considered to have mild HIP if BP was $\leq 160 / 110 \mathrm{mmHg}$, and severe HIP if BP was $>$ $160 / 110 \mathrm{mmHg}$

All cases and controls had their cord blood sampled immediately after delivery. This was done following doubleclamping and cutting the cord in between the clamps, then inserting the syringe at the placental end of the cord proximally and collecting about $4 \mathrm{~mL}$ of cord blood. The cord blood was analysed for full blood count, including haemoglobin concentration, white blood cell count, and platelet count, using the 3-part autoanalyser (Sysmex model $\mathrm{Kx} 21 \mathrm{~N}()$. Haematocrit was done manually using plain capillary tubes $(75 \mathrm{~mm}$ long with $1 \mathrm{~mm}$ bore and $0.2 \mathrm{~mm}$ to $0.25 \mathrm{~mm}$ wall thickness), as it is recommended that only haematocrit values determined by microcentrifugation or spun technique be used to screen infants with suspected polycythaemia. ${ }^{14}$ Peripheral blood film analysis was done to confirm white blood cell counts, carry out differential white blood cell counts, calculate corrected white blood cell counts (where necessary), and confirm platelet counts. All tests were carried out in duplicate and the mean of the two test taken.

Neonates were considered polycythaemic if their haematocrit was $65 \%$ or greater, neutropenic if their absolute neutrophil count was less than $1.5 \times 10^{9} / \mathrm{L}$; and thrombocytopenic if their platelet count was less than $90 \times 10^{9} / \mathrm{L}$.

\section{Statistical analysis}

Data were analysed using the Statistical Package for Social Sciences (SPSS) software (version 16). Means, standard deviations (SD), and percentages were calculated for the various measurements and variables obtained during data collection. Student's t-test and analysis of variance (ANOVA) were used, as appropriate, to compare the means of numerical parameters, while Chi-square and Fisher's Exact test were used, as appropriate, to compare qualitative parameters between the groups. A P-value of 0.05 or less was considered significant.

\section{Ethical considerations}

Ethical approval for this study was obtained from the University of Port Harcourt Research Ethical Committee, and it was carried out in accordance with the Declaration of Helsinki. Informed consent was obtained from the parents or caregivers of the neonates.

\section{Results}

The mean age, parity, and gravidity of women with HIP and those of the controls are presented in Table 1. Likewise, the mean GA at diagnosis, family history of hypertension, hypertension in previous pregnancies, severity of hypertension, and mode of delivery are shown in Table 1. Mothers who had live births were recruited for both groups; the cases had 53 males and 47 females, while the controls had 45 males and 55 females. The average birthweight of 
babies delivered by women with HIP was $2.98 \pm 0.8 \mathrm{~kg}$, while that of the controls was $3.3 \pm 0.5 \mathrm{~kg}$; this difference was statiscally significant $(\mathrm{P}=0.05)$.

The haematologic parameters of both groups were as presented in Table 2. The mean haematocrit and mean haemoglobin concentration of babies delivered to women with HIP were significantly higher than those of the controls. Similarly, the lymphocyte and monocyte counts were significantly higher in babies of women with HIP but the neutrophil and platelet counts were significantly lower. There was no significant difference in the other white blood cell differentials.

Table 1: Demographic characteristics, hypertension history, mode of delivery, and birth outcome

\begin{tabular}{|c|c|c|c|c|c|c|c|}
\hline \multirow[t]{2}{*}{ Variables } & \multirow{2}{*}{$\begin{array}{l}\text { Subjects with } \\
\text { hypertension in } \\
\text { pregnancy } \\
(\text { mean } \pm S D) \\
n=100\end{array}$} & \multirow{2}{*}{$\begin{array}{l}\text { Normal pregnant } \\
\text { women } \\
(\text { mean } \pm \mathrm{SD}) \\
\mathrm{n}=100\end{array}$} & \multirow[t]{2}{*}{ P-value } & \multicolumn{3}{|c|}{ Table 2: Neonatal haematology results } & \multirow{4}{*}{ P-value } \\
\hline & & & & \multirow{3}{*}{ Haematological indices } & \multirow{3}{*}{$\begin{array}{l}\text { Neonates of women } \\
\text { with hypertension in } \\
\text { pregnancy } \\
(\text { mean } \pm \text { SD }) \\
n=100\end{array}$} & \multirow{3}{*}{$\begin{array}{l}\text { Neonates of normal } \\
\text { pregnant women } \\
(\text { mean } \pm \text { SD) } \\
n=100\end{array}$} & \\
\hline Age (years) & $31.7 \pm 4.1$ & $30.7 \pm 5.4$ & 0.109 & & & & \\
\hline Parity & $1.5 \pm 1.2$ & $1.7 \pm 1.4$ & 0.339 & & & & \\
\hline Gravidity & $3.6 \pm 1.7$ & $3.1 \pm 1.6$ & 0.053 & Haematocrit (\%) & $51.1 \pm 9.0$ & $45.5 \pm 7.5$ & $<0.001$ \\
\hline GA at diagnosis (weeks) & $32.9 \pm 7.5$ & NA & NA & Haemoglobin $(\mathrm{g} / \mathrm{dL})$ & $16.6 \pm 3.1$ & $14.8 \pm 2.3$ & $<0.001$ \\
\hline \multirow[t]{2}{*}{ GA at delivery (weeks) } & $37.8 \pm 3.1$ & $38.6 \pm 2.1$ & 0.019 & WBC $\left(\times 10^{9} / \mathrm{L}\right)$ & $11.1 \pm 5.2$ & $10.6 \pm 4.3$ & 0.443 \\
\hline & Frequency (\%) & Frequency $(\%)$ & & Corrected WBC $\left(\times 10^{9} / \mathrm{L}\right)$ & $10.2 \pm 4.3$ & $10.0 \pm 4.1$ & 0.847 \\
\hline $\begin{array}{l}\text { Positive family history of } \\
\text { hypertension }\end{array}$ & $35(35.0)$ & $28(28.0)$ & 0.287 & Neutrophils (× 109/L) & $4.5 \pm 3.1$ & $5.4 \pm 2.7$ & 0.033 \\
\hline Diagnosis & & & & Bands $\left(\times 10^{9 / L}\right)$ & $0.59 \pm 0.05$ & $0.53 \pm 0.04$ & 0.404 \\
\hline Chronic hypertension & $16(16.0)$ & NA & NA & Metamyelocytes $\left(\times 10^{9} / \mathrm{L}\right)$ & $0.24 \pm 0.03$ & $0.22 \pm 0.02$ & 0.666 \\
\hline Gestational hypertension & $28(28.0)$ & NA & NA & Myelocytes $\left(\times 10^{9 / \mathrm{L})}\right.$ & $0.11 \pm 0.02$ & $0.11 \pm 0.01$ & 0.876 \\
\hline Preeclampsia & $46(46.0)$ & NA & NA & Promyelocytes $(\times 109 / \mathrm{L})$ & $0.04 \pm 0.01$ & $0.05 \pm 0.01$ & 0.463 \\
\hline Eclampsia & $10(10.0)$ & NA & NA & Myeloblasts (× 109/L) & $0.03 \pm 0.01$ & $0.03 \pm 0.01$ & 0.726 \\
\hline \multirow{2}{*}{$\begin{array}{l}\text { Previous history of } \\
\text { hypertension in pregnancy }\end{array}$} & \multirow{2}{*}{$34(34.0)$} & \multirow{2}{*}{$10(10.0)$} & \multirow{2}{*}{$<0.001$} & Eosinophils $\left(\times 10^{9} / \mathrm{L}\right)$ & $0.03 \pm 0.01$ & $0.03 \pm 0.01$ & 0.924 \\
\hline & & & & Basophils (× 109/L) & $0.02 \pm 0.00$ & $0.01 \pm 0.00$ & 0.125 \\
\hline \multicolumn{2}{|l|}{ Severity of hypertension } & & \multirow[b]{2}{*}{ NA } & Lymphocytes $\left(\times 10^{9} / \mathrm{L}\right)$ & $4.3 \pm 1.6$ & $3.6 \pm 2.0$ & 0.006 \\
\hline Mild & $21(21.0)$ & NA & & Monocytes $\left(\times 10^{9} / \mathrm{L}\right)$ & $0.14 \pm 0.03$ & $0.08 \pm 0.01$ & 0.030 \\
\hline Severe & $79(79.0)$ & NA & NA & Platelets $\left(\times 10^{9} / \mathrm{L}\right)$ & $157 \pm 106$ & $212 \pm 88$ & $<0.001$ \\
\hline $\begin{array}{l}\text { Number already on } \\
\text { therapy }\end{array}$ & $55(55.0)$ & NA & NA & \multicolumn{2}{|c|}{$\mathrm{SD}=$ standard deviation; $\mathrm{WBC}=$ white blood cells } & & \\
\hline
\end{tabular}

Mode of delivery

$\begin{array}{llll}\text { Spontaneous vertex } & 28(28) & 79(79.0) & <0.001 \\ \text { Elective caesarean section } & 25(25.0) & 10(10.0) & <0.001 \\ \text { Emergency caesarean section } & 47(47.0) & 11(11.0) & <0.001\end{array}$

Birth outcome

Sex

$\begin{array}{llll}\text { Male } & 53(53.0 \%) & 45(45.0 \%) & 0.256 \\ \text { Female } & 47(47.0 \%) & 55(55.0 \%) & 0.256 \\ \text { Birthweight }(\mathbf{k g}) & 2.98 \pm 0.8 & 3.3 \pm 0.5 & 0.005\end{array}$

$\mathrm{SD}=$ standard deviation; $\mathrm{GA}=$ gestational age; $\mathrm{NA}=$ not applicable

Table 4: Mean haematocrits, absolute neturophil counts, and platelet counts among neonates born to mothers with different hypertensive disorders of pregnancy

\begin{tabular}{|c|c|c|c|c|c|c|c|c|}
\hline $\begin{array}{l}\text { Haematological } \\
\text { indices }\end{array}$ & $\begin{array}{l}\text { Neonates of } \\
\text { women with } \\
\text { chronic } \\
\text { hypertension } \\
\text { (mean } \pm \text { SD) }\end{array}$ & $\begin{array}{l}\text { Neonates of } \\
\text { women with } \\
\text { gestational } \\
\text { hypertension } \\
\text { (mean } \pm \text { SD) }\end{array}$ & $\begin{array}{l}\text { Neonates of } \\
\text { women with } \\
\text { preeclampsia } \\
(\text { mean } \pm \text { SD) }\end{array}$ & $\begin{array}{l}\text { Neonates of } \\
\text { women with } \\
\text { eclampsia } \\
(\text { mean } \pm \text { SD) }\end{array}$ & P-value & $\begin{array}{c}\text { Cases } \\
\text { mean } \pm S D\end{array}$ & $\begin{array}{c}\text { Controls } \\
\text { mean } \pm \text { SD }\end{array}$ & P-value \\
\hline Haematocrit (\%) & $53.0 \pm 7.9$ & $51.3 \pm 10.4$ & $50.6 \pm 8.7$ & $49.6 \pm 9.2$ & 0.77 & $51.1 \pm 9.0$ & $45.5 \pm 7.5$ & $<0.001$ \\
\hline $\begin{array}{l}\text { Absolute neutrophil } \\
\text { count }\left(\times 10^{9} / \mathrm{L}\right)\end{array}$ & $3.8 \pm 2.7$ & $4.9 \pm 4.2$ & $4.4 \pm 2.6$ & $4.7 \pm 3.4$ & 0.74 & $4.5 \pm 3.1$ & $5.4 \pm 2.7$ & 0.03 \\
\hline Platelet count $\left(\times 10^{9} / \mathrm{L}\right)$ & $172.0 \pm 112.5$ & $157.8 \pm 106.8$ & $146.9 \pm 96.0$ & $178.3 \pm 146.1$ & 0.77 & $157 \pm 106$ & $212 \pm 88$ & $<0.001$ \\
\hline
\end{tabular}

Eight $(8 \%)$ of the babies delivered to women with HIP had polycythaemia, compared to zero among the controls (see Table 3). The haematocrit range in the polycythaemic neonates was $65 \%$ to $72 \%$. Fifteen $(15 \%)$ of the cases had neutropenia, while $2(2 \%)$ of the controls had neutropenia. Thirty eight $(38 \%)$ of babies of women with HIP had thrombocytopenia, compared to $8(8 \%)$ of the controls. Out of the 38 neonates with thrombocytopenia in the case group, $5 \%$ had both polycythaemia and thrombocytopenia, $6 \%$ had both neutropenia and thrombocytopenia, while one neonate had polycythaemia, neutropenia, and thrombocytopenia.

Haematocrit, absolute neutrophil count, and platelet count did not differ significantly between babies delivered to women in the various subtypes of hypertension in pregnancy (see Table 4).

Table 3: Incidence of neonatal polycythaemia, neutropenia, and thrombocytopenia

\begin{tabular}{|c|c|c|c|}
\hline Variables & $\begin{array}{l}\text { Neonates of women } \\
\text { with hypertension in } \\
\text { pregnancy } \\
\text { mean } \pm \text { SD } \\
N=100\end{array}$ & $\begin{array}{l}\text { Neonates of normal } \\
\text { pregnant women } \\
\text { mean } \pm \text { SD } \\
N=100\end{array}$ & P-value \\
\hline Polycythaemia & $8(8.0)$ & $0(0.0)$ & 0.007 \\
\hline Neutropenia & $15(15.0)$ & $2(2.0)$ & 0.002 \\
\hline Thrombocytopenia & $38(38.0)$ & $8(8.0)$ & $<0.001$ \\
\hline
\end{tabular}




\section{Discussion}

HIP is a major health burden; it is a leading cause of pregnancy-related maternal and neonatal morbidity and mortality. ${ }^{4}$ This study was conducted to evaluate the haematological indices in neonates of hypertensive mothers, paying special attention to haematocrit, neutrophil, and platelet counts in an African population known to have a high prevalence of hypertension and relatively lower blood count values compared to Caucasians.

We observed that the mean haematocrit was significantly increased in newborns of women with HIP, compared to those of normotensive mothers. Various researchers have evaluated the haematological profiles of newborns of women with HIP and have shown conflicting outcomes. ${ }^{7,8,9,10}$ However, this study was not restricted to a particular type of HIP, which each could have had varying proportions of newborns with intrauterine growth restriction (IUGR), but focused on all forms of HIP, whose mean birthweight was high enough to have eliminated the bias attributable to IUGR. Polycythaemia was significantly higher in cases than in the controls. This may be explained by the relative hypoxia, suffered by the foetus in a pregnancy complicated by hypertension, which stimulates the release of erythropoietin, which in turn promotes erythropoiesis, leading to neonatal polycythaemia. Increased levels of erythropoietin have been observed in the cord blood of neonates of mothers with HIP, contributing to the pathogenesis of polycythaemia. ${ }^{10}$

Also observed was a significantly lower mean absolute neutrophil count in the cases compared to controls. Fifteen percent of the cases in this study had neutropenia, compared to $2 \%$ in the controls. There is no known mechanism of neutropenia in HIP, but it has been proposed that neonates of hypertensive mothers have reduced numbers of myeloid precursors, resulting from uteroplacental insufficiency and the resultant hypoxia that inhibits their production. ${ }^{15}$ Activation of the Fas/Fas ligand pathway of apoptosis has been proposed as a contributory mechanism to the pathogenesis of neutropenia in neonates of women with HIP. ${ }^{16}$ The increased apoptotic activity of myeloid precursors may contribute to neutropenia in HIP. In addition, diminished levels of the granulocyte colony stimulating factor (G-CSF) may play a role in the mechanism of neutropenia, as obseverved in two separate studies. ${ }^{17,18}$ It may also be true that GA determines the neutrophil count, as suggested by this study. Again, this study was carried out on black subjects and racial variations observed in the distribution of circulating neutrophil counts should be considered when interpreting the results, as Caucasians are known to have higher circulating neutrophils than blacks. ${ }^{12}$ Also observed in this study were higher mean lymphocyte and monocyte counts in neonates among the cases than in the control group. We could not explain the higher mean lymphocyte count, but increased monocyte count is thought to be associated with lower birthweight and GA, as was the seen among the cases. This could be because some mothers of these low birthweight neonates received steroids for foetal lung maturation, which could cause increase in monocyte count as a response to foetal bone marrow stimulation. ${ }^{19}$

The mean platelet count of neonates of hypertensive mothers was found to be significantly lower than that of normotensive mothers. It should be noted that the cut-off value for thrombocytopenia in this study was set at $90 \times$ $10^{\circ} / \mathrm{L}$. This is because Africans are known to have lower platelet counts. ${ }^{13}$ This notwithstanding, it is possible to have some degree of thrombocytopenia in neonates because of the limited ability of infants to increase platelet production, as their megakaryocytes tend to be smaller and of lower ploidy than those of adults. ${ }^{20}$ Hypertension-induced foetal hypoxia is thought to have a direct depressant effect on megakaryocyte proliferation. ${ }^{21}$ The incidence of thrombocytopenia is also known to decrease with increasing gestational age, explaining the higher incidence observed in a few other studies involving subjects delivered at an earlier gestational age. ${ }^{22}$ This study also corroborates the observation that gestational age is an independent determinant of platelet count.

There was no significant difference in the mean haematocrit, absolute neutrophil count, or platelet count between the newborns of women with various subtypes of HIP, probably because fewer women $(16 \%)$ had chronic hypertension, a subtype associated with the severest form of placental insufficiency and hence more foetal manifestations. ${ }^{7}$ Furthermore, the majority of these women were on antihypertensive therapy, mitigating the effect of high blood pressure on the placental circulation during the first half of pregnancy.

Apart from the effect of HIP on the haematological parameters of neonates, this study also observed a lower mean birthweight in the case group than among controls, even after being matched for gestational age. However, the mean weight among cases was within the normal range. It was also observed that there was a higher incidence of operative delivery among women with HIP than in controls. Furthermore, there was no significant difference in the mean haematocrit, absolute neutrophil count, or platelet count among the various modes of delivery.

\section{Conclusions}

This study, carried out in the Niger-Delta region of Nigeria, has documented a significantly higher haematocrit with lower absolute neutrophil and platelet counts in neonates of women with HIP, compared to controls.

The study did not find any significant differences in the haematological profiles of the neonates of mothers with the various subtypes of hypertension in pregnancy.

\section{References}

1. Gelband H, Liljestrand J, Nemer L, Islam M, Zupan J. The evidence base for to reduce maternal and neonatal mortality in low and middle-income countries. Geneva, Switzerland, World Health Organisation (WHO), Commission on Macroeconomics and Health, (2002). (102)p. (CWH Working Paper Series No. 5). (accessed on March 4, 2016). Available at http://www.popline.org/node/563083.

2. American College of Obstetricians and Gynaecologists practice bulletin. Diagnosis and management of preeclampsia and eclampsia. Int J Gynaecol Obstet. 2002;77(33): 67-75.

3. McCaw Binns AM, MacGillivray I, Hawkins N, Golding J, Ashley DEC. International variation in the incidence of hypertension in pregnancy among primiparae: the Jamaican experience. West Indian Med J. 1997;46(2):29-32.

4. Report of the National High Blood Pressure Education Programme (NHBPEP) Working Group on High Blood Pressure in Pregnancy. Am J Obstet Gynecol. 2000; 183:S1-S22.

5. Chang J, Elam-Evans LD, Berg CJ, Herndon J, Flowers L, Seed KA, Syverson CJ. Pregnancy-related mortality surveillance in the United States, 1991-1999. MMWR Surveillance Summary. 2003; 52(SS02):1-8.

6. Schroeder BM. American College of Obstetricians and Gynecologists. ACOG practice bulletin on diagnosing and managing pre-eclampsia and eclampsia. Am Fam Physician. 2002;66(2):330-331. 
7. Onyiriuka A N, Okolo AA. Small-for-gestational age, ponderal index and neonatal polycythemia: a study of their association with maternal hypertension among Nigerian women. Ann Afr Med. 2005;4(4):154-159.

8. Kurlat I, Sola A. Neonatal polycythemia in appropriately grown infants of hypertensive mothers. Acta Paediatr.1992; 81(9):666-674.

9. Gray PH, Rodwell RL. Neonatal neutropenia associated with maternal hypertension poses a risk for nosocomial infection. Eur J Paediatr.1999;158(1):71-73.

10. Sivakumar S, Bhat BV, Badhe BA. Effects of pregnancy-induced hypertension on mothers and their babies. Indian J Pediatr. 2007;74 (7): 623-625.

11. Duley L. The global impact of pre-eclampsia and eclampsia. Semin in perinatol. 2009; 33(3):130-137.

12. Bain BJ. Ethnic and sex differences in the total and differential white cell count and platelet count. J Clin Pathol. 1996 Aug; 49(8) 664-66.

13. Essien EM, Usanga EA, Ayeni O. The normal platelet count and platelet factor 3 availability in some Nigerian population groups. Scand J Haematol. 1973;10(5):378-83.

14. Stevens K, Wirth FH. Incidence of neonatal hyperviscosity at sea level. J pediatr. 1980;97:118-119.

15. Koenig JM, Christensen RD. The mechanism responsible for diminished neutrophil production in neonates delivered of women with pregnancy-induced hypertension. Am J Obstet Gynecol. 1991
Aug;165(2)467-73.

16. Neale DM, Mor G. The role of Fas mediated apoptosis in preeclampsia. J Perinat Med. 2005; 33:471-477.

17. Russell AR, Davies EG, McGuigan S, Scopes GJ, Gordon-Smith EC. Plasma granulocyte-colony stimulating factor (G-CSF) concentrations in early neonatal period. Br J Haematol. 1994; 86:642-644.

18. Tsao PN, Teng RJ,Tang JR, Yau KT. Granulocyte colony stimulating factor in the cord blood of premature neonates born to mothers with pregnancy-induced hypertension. J Pediatr. 1999; 135(1):56-59.

19. Rajadurai VS, Chambers HM, Vigneswaran R, Gardiner AA. Monocytosis in preterm infants. Early Hum Dev. 1992;28(3):223-229.

20. Diz-Kucukkaya R, Chen J, Geddis A, Lopez JA. Thrombocytopenia In: Kaushansky K, Lichtman MA, Beutler E, Kipps TJ, Seligsohn U, Prchal JT, editors. Williams Heamatology, 8th edn. McGraw-Hill companies, China. 2010; 119: 1916-1917.

21. Weiner CP, Williamson RA. Evaluation of severe growth retardation using cordocentesis - hematologic and metabolic alterations by etiology. J Obstet Gynecol. 1989; 73(2):225-229.

22. Robert I, Murray NA. Neonatal thrombocytopenia. Seminars in fetal and neonatal medicine. 2008; 13: 256-264. 